\title{
Trends of infant mortality and its determinants in Ethiopia: mixed-effect binary logistic regression and multivariate decomposition analysis
}

Getayeneh Antehunegn Tesema', Wullo Sisay Seretew ${ }^{1 *}$, Misganaw Gebrie Worku² and Dessie Abebaw Angaw ${ }^{1}$

\begin{abstract}
Background: Infant mortality remains a serious global public health problem. The global infant mortality rate has decreased significantly over time, but the rate of decline in most African countries, including Ethiopia, is far below the rate expected to meet the SDG targets. Therefore, this study aimed to investigate the trends of infant mortality and its determinants in Ethiopia based on the four consecutive Ethiopian Demographic and Health Surveys (EDHSs).

Methods: This analysis was based on the data from four EDHSs (EDHS 2000, 2005, 2011, and 2016). A total weighted sample of 46,317 live births was included for the final analysis. The logit-based multivariate decomposition analysis was used to identify significantly contributing factors for the decrease in infant mortality in Ethiopia over the last 16 years. To identify determinants, a mixed-effect logistic regression model was fitted. The Intra-class Correlation Coefficient (ICC) and Likelihood Ratio (LR) test were used to assess the presence of a significant clustering effect. Deviance, Akaike Information Criteria (AIC), and Bayesian Information Criteria (BIC) were used for model comparison. Variables with a $p$-value of less than 0.2 in the bi-variable analysis were considered for the multivariable analysis. In the multivariable analysis, the Adjusted Odds Ratio (AOR) with 95\% Confidence Interval (Cl) were reported to identify the statistically significant determinants of infant mortality.
\end{abstract}

Results: Infant mortality rate has decreased from 96.9 per 1000 births in 2000 to 48 per 1000 births in 2016, with an annual rate of reduction of $4.2 \%$. According to the logit based multivariate decomposition analysis, about $18.1 \%$ of the overall decrease in infant mortality was due to the difference in composition of the respondents with respect to residence, maternal age, type of birth, and parity across the surveys, while the remaining $81.9 \%$ was due to the difference in the effect of residence, parity, type of birth and parity across the surveys. In the mixed-effect binary logistic regression analysis; preceding interval $<24$ months ( $A O R=1.79,95 \% \mathrm{Cl} ; 1.46,2.19$ ), small size at birth $(A O R=1.55,95 \% \mathrm{Cl} ; 1.25,1.92)$, large size at birth $(A O R=1.26,95 \% \mathrm{Cl} ; 1.01,1.57), \mathrm{BMl}<18.5 \mathrm{~kg} / \mathrm{m}^{2}(\mathrm{AOR}=1.22,95 \%$ $\mathrm{Cl} ; 1.05,1.50)$, and twins $(\mathrm{AOR}=4.25,95 \% \mathrm{Cl} ; 3.01,6.01)$, parity $>6(1.51,95 \% \mathrm{Cl} ; 1.01,2.26)$, maternal age and male sex $(A O R=1.50,95 \% \mathrm{Cl}: 1.25,1.79)$ were significantly associated with increased odds of infant mortality.

\footnotetext{
* Correspondence: wsisay2733@gmail.com

'Department of Epidemiology and Biostatistics, institute of public health,

college of medicine and health science, University of Gondar, Gondar,

Ethiopia

Full list of author information is available at the end of the article
}

(c) The Author(s). 2021 Open Access This article is licensed under a Creative Commons Attribution 4.0 International License, which permits use, sharing, adaptation, distribution and reproduction in any medium or format, as long as you give appropriate credit to the original author(s) and the source, provide a link to the Creative Commons licence, and indicate if changes were made. The images or other third party material in this article are included in the article's Creative Commons licence, unless indicated otherwise in a credit line to the material. If material is not included in the article's Creative Commons licence and your intended use is not permitted by statutory regulation or exceeds the permitted use, you will need to obtain permission directly from the copyright holder. To view a copy of this licence, visit http://creativecommons.org/licenses/by/4.0/. The Creative Commons Public Domain Dedication waiver (http://creativecommons.org/publicdomain/zero/1.0/) applies to the data made available in this article, unless otherwise stated in a credit line to the data. 


\begin{abstract}
(Continued from previous page)
Conclusion: This study found that the infant mortality rate has declined over time in Ethiopia since 2000.

Preceding birth interval, child-size at birth, BMl, type of birth, parity, maternal age, and sex of child were significant

predictors of infant mortality. Public health programs aimed at rural communities, and multiparous mothers

through enhancing health facility delivery would help maintain Ethiopia's declining infant mortality rate.

Furthermore, improving the use of ANC services and maternal nutrition is crucial to reducing infant mortality and

achieving the SDG targets in Ethiopia.
\end{abstract}

Keywords: Infant mortality, Mixed effect analysis, Multivariate decomposition analysis, Ethiopia

\section{Background}

The death of a child during the first year of life is called infant mortality [1]. The global infant mortality has fallen dramatically from 8.8 million in the last two decades to 4.1 million [2] and the rate dropped from 65 deaths per 1000 live births in 1990 to 29 deaths per 1000 live births in 2017 [3]. Despite the substantial decline in global infant mortality, low-and middle-income countries still bear the enormous burden of infant mortality $[2,4,5]$. Ethiopia is one of the countries with a high infant mortality rate (48 per 1000 live births) in Africa [6]. Nearly $80 \%$ of infant deaths are from preventable causes [7].

Infant mortality is one of the commonest healthrelated indicators used to assess the health status of the community [8]. Despite the progress made by many countries to achieve the Millennium Development Goal (MDG) 4 to reduce child mortality by two-thirds [9]; half of the world's nations including Ethiopia are still behind their targets and MDG-4 continued as unfinished agenda [10].

The Ethiopian government strongly motivated to improve maternal-child and maternal health for the last two decades [11] but infant mortality remains a significant health care problem in the country [12]. It has reduced from 123 per 1000 births in 1990 to 48 per 1000 births in 2015 but it is far below the national target [13, 14]. According to the Ethiopian Demographic and Health Surveys (EDHSs), the infant mortality rate has declined from 97 per 1000 live births in 2000 [15] to 48 per 1000 live births in 2016 [6] with a huge disparity across regions and within countries [12].

Maternal age [16, 17], maternal education status [18, 19], household wealth status [20], Antenatal Care (ANC) visit during pregnancy [21, 22], parity [23], birth order [24], place of delivery [25, 26], child nutritional status (stunting, wasting and underweight) [26], vaccination status [27], and residence [28] were reported by previous researchers as significant predictors of infant mortality.

Though infant mortality rates have decreased over time in Ethiopia, previous studies were focused on the prevalence and associated factors of infant mortality only $[21,29,30]$ and failed to capture the trends and determinants of infant mortality in Ethiopia over time using a Logit based Multivariate Decomposition analysis for Non-linear Response Model (MVDCMP) and Generalized Linear Mixed Model (GLLM). Therefore, this study aimed to investigate the trend and determinants of infant mortality in Ethiopia over time. Understanding the trends and determinants of infant mortality could help public health planners, and partners to design evidence-based interventions to effectively reduce infant mortality in Ethiopia.

\section{Methods and materials Data sources}

A community-based time-series cross-sectional study was used to answer the research objectives. All the Demographic and Health Surveys (DHSs) (EDHS 2000, 2005, 2011, and 2016) conducted in Ethiopia were used. The EDHS was employed in every five-year interval to generate updated health and health-related indicators. The majority of the country's population lives in the regional states of Amhara, Oromia, and Southern Nations Nationalities and People's Regions (SNNPR) [25]. Ethiopia is the 13th in the world and 2nd most populous country in Africa [26]. In 2016, there were an estimated 102 million people.

A two-stage sampling technique was employed to select the sample and a total of 539 Enumeration Areas (EAs) in EDHS 2000, 540 EAs in EDHS 2005, 624 EAs in EDHS 2011, and 645 EAs in EDHS 2016 were randomly selected. Then, on average 27 to 32 households per EA were selected. The source population was all live births from reproductive-age women within 5 years before the survey in Ethiopia whereas all live births from reproductive-age women in the selected enumeration areas were the study population. A total weighted sample of 46,317 live births (12,260 in EDHS 2000, 11,163 in EDHS 2005, 11,872 in EDHS 2011, and 11,022 in EDHS 2016) from reproductive-age women were used for analysis. The detailed sampling procedure was presented in the full EDHSs report $[18,19,31,32]$.

\section{Study variables}

The outcome variable for this study was infant mortality (the death of live birth within 1 year of birth). In EDHS 
there was a question about whether the child was alive or died at the time of the survey and for dead infantsage at death were recorded. Death of a child within 1 year of age was coded as 1 , and 0 if the child was alive. The unit of analysis in this study was all live births in the 5 years preceding the survey. The infant mortality rate is defined as the number of infant deaths per 1000 live births [33]. The independent variables considered in this study were region (coded as Tigray, Afar, Amhara, Oromia, Somali, Benishangul, SNNPR, Gambella, Harari, Addis Ababa, and Dire Dawa), residence (coded as rural, and urban), sex of household head (coded as male and female), maternal age (recoded as <20, 20-29, 30-39 and $40-49$ years), women education (recoded as no, primary, and secondary and higher), paternal education (recoded as no, primary, and secondary and above), preceding birth interval (recoded as $<24$ and $\geq 24$ months), Body Mass Index (BMI) of the mother (recoded as < $18.5,18.5-24.9$, and $\geq 25 \mathrm{~kg} / \mathrm{m}^{2}$ ), wealth index (coded as poor, middle and rich), parity (recoded as 1-3, 4-6 and $>6$ births), type of birth (coded as single and multiple), place of delivery (coded as home and health facility), ANC visit during pregnancy (no visit, 1-4 and $>4$ ANC visits), cigarettes smoking (coded as no and yes), mode of delivery (coded as vaginal and caesarean delivery), child nutritional status (stunting; coded as normal, moderately stunted, and severely stunted; wasting coded as normal, moderately wasted, and severely stunted; and underweight coded as normal, moderately underweight and severely underweight), media exposure (coded as no and yes), religion (coded as orthodox, muslim, protestant, catholic and others), sex of child (coded as male and female), covered by health insurance (coded as no and yes), and birth weight (large, average and small).

Wealth Index (WI) was considered as a living standard measure for each respective year and generated using the Principal Component Analyses (PCA). The variables included in the PCA were ownership of durable assets, like radios, cars, refrigerators, TV sets, motorcycles, and bicycles; housing characteristics, such as the number of rooms for sleeping and building materials (walls, floors, and roofs); access to utilities and infrastructures, like electricity supply, source of drinking water, and sanitation facilities.

\section{Data management and analysis}

The Ethiopian Demographic and Health survey consists of different datasets including men, women, kids (KR), birth, household, and household datasets. For this study, we used the Kids Record (KR) data set. The data were weighted using sampling weight, primary sampling unit, and strata before any statistical analysis to restore the representativeness of the survey to get reliable statistical estimates. Descriptive and summary statistics were done using STATA version 14 software.

\section{Trend analysis}

For the decomposition analysis, we appended the extracted data of 2000, 2005, 2011 and 2016 using the STATA command "append using" after we kept the similar variables across the surveys. The change in infant mortality rate in Ethiopia for the last 16 years was examined.

To determine the factors that contributed to the decrease in the infant mortality rate over the last 16 years, the Multivariate Decomposition Analysis for the Nonlinear Response variable (MVDCMP) was used. The multivariate decomposition analysis based on the logit link function uses the output from the binary logistic regression model to divide into components. The decrease in infant mortality can be explained by the difference in composition between the surveys (i.e., differences in characteristics or endowment) and/or the difference in effects of the explanatory variables across the surveys (i.e., differences in coefficients).

The multivariate decomposition analysis of the logit or log-odd of infant mortality is taken as:

$$
\begin{aligned}
& \operatorname{Logit}(\mathrm{A})-\operatorname{Logit}(\mathrm{B})=\mathrm{F}(\mathrm{XA} \beta \mathrm{A})-\mathrm{F}(\mathrm{XB} \beta \mathrm{B}) \\
& \frac{=[\mathrm{F}(\mathrm{XA} \beta \mathrm{A})-\mathrm{F}(\mathrm{XB} \beta \mathrm{A})]}{\mathrm{E}}+\frac{[\mathrm{F}(\mathrm{XB} \beta \mathrm{A})-\mathrm{F}(\mathrm{XB} \beta \mathrm{B}]}{\mathrm{C}}
\end{aligned}
$$

The E component refers to the part of the overall decrease in infant mortality explained by the change in the composition of the study participants across the surveys. There is no error term in the logit-based multivariate decomposition analysis because we used the logit link function. The $\mathrm{C}$ component refers to the percentage of the overall decrease in infant mortality attributable to the differences in coefficients or effects of the explanatory variable across the surveys. For the decomposition analysis of infant mortality using the mvdcmp STATA command (28). Variables with a $p$-value $<0.2$ in the bivariable Logit-based multivariate decomposition analysis were considered for the multivariable Logit-based multivariate decomposition analysis. Finally, $p$-value $<0.05$ and the corresponding coefficient $(B)$ with a $95 \%$ confidence interval were used to declare significant factors that contributed to the decrease in infant mortality.

\section{Determinants of infant mortality}

As the data used for this study had nested structure, infants within the same cluster might share similar characteristics than infants out of that cluster. In hierarchical data, advanced statistical models such as mixed-effect regression analysis to get reliable estimate. Therefore, a two-level mixed-effect logistic regression model (both fixed and random effect) was fitted using EAs as a random variable to draw a valid conclusion. The assumptions of the mixed-effect binary logistic regression model were checked using the Intra-class Correlation 
Coefficient (ICC) and Likelihood Ratio (LR) test. The Median Odds Ratio (MOR) and Proportional Change in Variance (PCV) were computed to measure the variation across clusters. ICC quantifies the degree of heterogeneity of infant mortality between clusters (the proportion of the total observed individual-level variation in infant mortality that is attributable to between cluster variations).

$$
\mathrm{ICC}=\sigma 2 /(\sigma 2+\pi 2 / 3)
$$

The MOR measures the between cluster variation in terms of odds ratio. The median value of the odds ratio between the cluster at high risk of infant mortality and cluster at lower risk of the infant when randomly picking out two clusters (EAs).

$$
\begin{aligned}
\mathrm{MOR} & =\exp (\sqrt{ }(2 * \partial 2 * 0.6745)) \sim \mathrm{MOR} \\
& =\exp (0.95 * \partial)
\end{aligned}
$$

$\partial 2$ indicates that cluster variance

PCV measures the total variation in infant mortality explained by the final model compared to the null model.

$$
\mathrm{PCV}=(\operatorname{var}(\text { null model })-\operatorname{var}(\text { full model })) /(\operatorname{var}(\text { null model }))
$$

Akaike Information Criteria (AIC), Bayesian Information Criteria (BIC), and deviance were used for model comparison and a model with the lower deviance was chosen since the model was nested. We identified the independent variables based on previous literature conducted on determinants of infant mortality. As the data used for this study was secondary there was missing on the outcome variable (age at death), and we drop the observation that has missing value on the outcome variables. In the bi-variable mixed-effect binary logistic regression analysis; residence, sex of household head, maternal age, maternal education, wealth status, maternal BMI, preceding birth interval, parity, covered by health insurance, size at birth, ANC visit during pregnancy, sex of the child, place of delivery and type of birth had a $p$-value less than 0.2 and were considered for multivariable analysis. However, in the multivariable analysis; parity, type of birth, maternal age, maternal BMI, number of ANC visits, preceding birth interval, sex of a child, and size at birth were significantly associated with infant mortality. The Adjusted Odds Ratio (AOR) with a 95\% Confidence Interval (CI) and $p$-value $<0.05$ in the multivariable model were used to declare significant determinant factors of infant mortality.

\section{Ethical consideration}

As the study was a secondary data analysis accessed from the MEASURE DHS program, this study did not require ethical approval and participant consent. We have granted permission from http:/www.dhsprogram. com to download and use the data for this study. In the data sets, there is no name of persons or household addresses.

\section{Results}

Characteristics of the study population

A total of 46,317 live births were included in this study. The non-response rate in EDHS 2000, EDHS 2005, EDHS 2011, and EDHS 2016 were 2.2, 4, 5 and 5\%, respectively. More than one-third of live births in all four surveys were found in the Oromia region. The proportion of mothers who had a primary level of education slightly increased from $13 \%$ in 2000 to $26.8 \%$ in 2016. Besides, the percentage of women who had media exposure has increased from 27.1 to $33.1 \%$ in the last 16 years. Regarding ANC visits during pregnancy, the percentage of women who had 1-4 ANC visits during pregnancy was increased from $19.8 \%$ in 2000 to $46.6 \%$ in 2016 . The percentage of health facility delivery has increased from 5.2 to $27.4 \%$ for the last 16 years (Table 1 ).

\section{Trends of infant mortality rate from 2000 to 2016}

The overall infant mortality rate has decreased from 96.9 [93.6, 104.2] per 1000 live births in 2000 to 48.0 [44.2, 52.2] to 1000 live births in 2016 with an Annual Rate of Reduction (ARR) of $4.2 \%$ (Fig. 1). The infant mortality rate has decreased across regions over time, it was decreased from 122 per 1000 live births in 2000 to 41 per 1000 live births in 2016 in the Gambella region (Fig. 2). Regarding the place of residence, there was a 54.2- and 51.5-point decrease in the infant mortality rate among urban residents and mothers who had no formal education over the last 16 years, respectively. The infant mortality rate among births in the health facility decreased by 66.1 per 1000 live births from 2000 to 2016 (Table 2).

\section{Decomposition analysis}

There was a significant decline in the infant mortality rate for the last 16 years (2000-2016). The overall multivariate decomposition analysis revealed that about $18.1 \%$ of the overall decrease in infant mortality rate over the last 16 years was attributable to the difference in endowment (composition) across the surveys whereas the remaining $81.9 \%$ was attributable to the difference in coefficient (effects of characteristics) over the surveys (Table 3). Among the difference in endowment; the difference in composition of rural residents $(B=-0.0006$, 95\% CI: $-0.0009,-0.0004, p=0.03)$, maternal age 3039 years $(B=0.0007,95 \% C I:-0.001,-0.0002, \quad p=$ 
Table 1 Characteristics of the study population in 2000, 2005, 2011 and 2016 Ethiopian Demographic and Health Surveys

\begin{tabular}{|c|c|c|c|c|}
\hline \multirow[t]{2}{*}{ Variables } & EDHS $2000(n=12,260)$ & EDHS $2005(n=11,163)$ & EDHS $2011(n=11,872)$ & $\begin{array}{l}\text { EDHS } 2016(n=11,022) \\
\text { Weighted frequency }(\%)\end{array}$ \\
\hline & Weighted frequency (\%) & Weighted frequency (\%) & Weighted frequency (\%) & \\
\hline \multicolumn{5}{|l|}{ Region } \\
\hline Tigray & $788(6.4)$ & $698(6.3)$ & $753(6.3)$ & $716(6.5)$ \\
\hline Afar & $126(1.0)$ & $107(1.0)$ & $121(1.0)$ & $114(1.0)$ \\
\hline Amhara & $3202(26.1)$ & $2621(23.5)$ & $2656(22.4)$ & $2072(18.8)$ \\
\hline Oromia & 4999 (40.9) & 4411 (39.5) & $5014(42.2)$ & $4851(44.2)$ \\
\hline Somali & $142(1.2)$ & $477(4.3)$ & $364(3.1)$ & $507(4.6)$ \\
\hline Benishangul & $124(1.0)$ & $105(0.9)$ & $140(1.2)$ & $122(1.1)$ \\
\hline SNNPRS & $2602(21.2)$ & $2500(22.4)$ & $2494(21.1)$ & $2296(20.8)$ \\
\hline Gambella & $29(0.2)$ & $31(0.3)$ & $40(0.3)$ & $27(0.2)$ \\
\hline Harari & $25(0.2)$ & $22(0.2)$ & $29(0.2)$ & $26(0.2)$ \\
\hline Addis Ababa & $182(1.5)$ & $153(1.3)$ & $221(1.9)$ & $244(2.2)$ \\
\hline Dire Dawa & $40(0.3)$ & $37(0.3)$ & $39(0.3)$ & $47(0.4)$ \\
\hline \multicolumn{5}{|l|}{ Place of residence } \\
\hline Urban & $1276(10.4)$ & $815(7.3)$ & $1528(12.9)$ & $1215(11.0)$ \\
\hline Rural & 10,984 (89.6) & $10,348(92.7)$ & $10,344(87.1)$ & 9807 (89.0) \\
\hline \multicolumn{5}{|l|}{ Religion } \\
\hline Orthodox & $6042(49.3)$ & 4674 (41.9) & $4519(38.1)$ & $3772(34.2)$ \\
\hline Catholic & $81(0.7)$ & $121(1.1)$ & $108(0.9)$ & $103(0.9)$ \\
\hline Protestant & 1959 (16.0) & 2217 (19.9) & $2758(23.2)$ & $2329(21.1)$ \\
\hline Muslim & $3713(30.3)$ & $3875(34.7)$ & $4214(35.5)$ & $4561(41.4)$ \\
\hline Others & 465 (3.8) & $275(2.5)$ & $271(2.3)$ & $257(2.3)$ \\
\hline \multicolumn{5}{|l|}{ Age of women (in years) } \\
\hline$<20$ & $557(4.6)$ & $575(5.2)$ & $491(4.1)$ & $378(3.4)$ \\
\hline $20-29$ & $6047(49.3)$ & $5415(48.5)$ & $6158(51.9)$ & $5421(49.2)$ \\
\hline $30-39$ & $4272(34.8)$ & $4019(36.0)$ & $4166(35.1)$ & $4261(38.7)$ \\
\hline$\geq 40$ & $1384(11.3)$ & $1154(10.3)$ & $1057(8.9)$ & $962(8.7)$ \\
\hline \multicolumn{5}{|l|}{ Maternal education } \\
\hline No education & $10,062(82.1)$ & $8838(79.2)$ & $8227(69.3)$ & $7284(66.1)$ \\
\hline Primary & $1597(13.0)$ & $1855(16.6)$ & $3211(27.0)$ & $2950(26.8)$ \\
\hline Secondary and higher & $601(4.9)$ & $470(4.2)$ & $434(3.7)$ & $788(7.1)$ \\
\hline \multicolumn{5}{|l|}{ Husband education } \\
\hline No & $7771(63.4)$ & $6508(58.3)$ & $4866(47.0)$ & $4116(37.3)$ \\
\hline Primary & $3026(24.7)$ & $3350(30.0)$ & $583(4.9)$ & $798(7.30$ \\
\hline Secondary and higher & $1463(11.9)$ & $1305(11.7)$ & $6422(54.1)$ & $6108(55.4)$ \\
\hline \multicolumn{5}{|l|}{ Sex of household head } \\
\hline Male & $10,589(86.4)$ & $9943(89.1)$ & $10,106(85.1)$ & $9494(86.1)$ \\
\hline Female & 1671 (13.6) & $1220(10.9)$ & $1766(14.9)$ & $1528(13.9)$ \\
\hline \multicolumn{5}{|l|}{ Maternal BMI (in $\mathrm{Kg} / \mathrm{m}^{2}$ ) } \\
\hline$<18.5$ & $2764(22.5)$ & $1109(9.9)$ & 2439 (20.6) & 2098 (19.0) \\
\hline $18.5-24.9$ & $9112(74.3)$ & $4146(37.1)$ & $8678(73.1)$ & $7953(72.2)$ \\
\hline$\geq 25$ & $384(3.1)$ & $5908(53.0)$ & $755(6.3)$ & $971(8.8)$ \\
\hline \multicolumn{5}{|c|}{ Number of ANC visit during pregnancy } \\
\hline No visit & $5789(72.7)$ & $5225(46.8)$ & $4516(57.1)$ & $2818(37.1)$ \\
\hline
\end{tabular}


Table 1 Characteristics of the study population in 2000, 2005, 2011 and 2016 Ethiopian Demographic and Health Surveys (Continued)

\begin{tabular}{|c|c|c|c|c|}
\hline \multirow[t]{2}{*}{ Variables } & EDHS $2000(n=12,260)$ & EDHS $2005(n=11,163)$ & EDHS $2011(n=11,872)$ & EDHS $2016(n=11,022)$ \\
\hline & Weighted frequency (\%) & Weighted frequency (\%) & Weighted frequency (\%) & Weighted frequency (\%) \\
\hline $1-4$ visits & $1573(19.8)$ & 4447 (39.8) & $2451(31.0)$ & $3536(46.6)$ \\
\hline$>4$ visits & $604(7.5)$ & $1491(13.4)$ & $940(1.9)$ & $1236(16.3)$ \\
\hline \multicolumn{5}{|l|}{ Child size at birth } \\
\hline Small & 4115 (33.6) & 3557 (31.9) & 3519 (29.6) & 2957 (26.8) \\
\hline Average & $4376(35.7)$ & $4462(40.0)$ & $4548(38.3)$ & 4580 (41.6) \\
\hline Large & $3769(30.7)$ & $3144(28.1)$ & 3805 (32.1) & 3485 (31.6) \\
\hline \multicolumn{5}{|l|}{ Place of delivery } \\
\hline Home & $11,625(94.8)$ & $10,502(94.1)$ & 10,627 (89.5) & 7997 (72.6) \\
\hline Health facility & $635(5.2)$ & $661(5.9)$ & $1245(10.5)$ & 3025 (27.4) \\
\hline \multicolumn{5}{|l|}{ Mode of delivery } \\
\hline Vaginal & $12,160(99.3)$ & $11,050(99.0)$ & $11,697(98.5)$ & $10,810(98.1)$ \\
\hline Caesarean section & $100(0.7)$ & $113(1.0)$ & $175(1.5)$ & $212(1.9)$ \\
\hline \multicolumn{5}{|l|}{ Type of birth } \\
\hline Single & 11,994 (97.8) & $10,963(98.2)$ & $11,597(97.7)$ & $10,730(97.4)$ \\
\hline Multiple & $266(2.2)$ & $200(1.8)$ & $275(2.3)$ & $292(2.6)$ \\
\hline \multicolumn{5}{|l|}{ Sex of infant } \\
\hline Male & $6288(51.3)$ & $5723(51.3)$ & $6168(52.0)$ & $5724(51.9)$ \\
\hline Female & $5972(48.7)$ & $5440(48.7)$ & $5704(48.0)$ & $5298(48.1)$ \\
\hline \multicolumn{5}{|c|}{ Ever had termination of pregnancy } \\
\hline No & $10,488(85.5)$ & $10,267(92.0)$ & 10,639 (89.6) & $10,056(91.2)$ \\
\hline Yes & $1772(14.5)$ & $896(8.0)$ & $1233(10.4)$ & $966(8.8)$ \\
\hline \multicolumn{5}{|l|}{ Stunting } \\
\hline Normal & $7644(62.4)$ & $9149(82.0)$ & $6893(58.1)$ & $6624(60.1)$ \\
\hline moderately stunted & $2292(18.7)$ & $980(8.8)$ & $2258(19.0)$ & $1802(16.3)$ \\
\hline Severely stunted & $2324(18.9)$ & $1034(9.2)$ & $2721(22.9)$ & $2596(23.6)$ \\
\hline \multicolumn{5}{|l|}{ Underweight } \\
\hline Normal & $7937(64.7)$ & $9487(85.0)$ & $7288(61.4)$ & $6998(63.5)$ \\
\hline Moderately underweight & $2837(23.1)$ & $1192(10.7)$ & $2615(22.0)$ & $2146(19.5)$ \\
\hline Severely underweight & $1486(12.2)$ & $484(4.3)$ & 1969 (16.6) & $1879(17.0)$ \\
\hline \multicolumn{5}{|l|}{ Wasting } \\
\hline Normal & $11,091(90.5)$ & $10,701(95.7)$ & $9896(83.4)$ & $8931(81.0)$ \\
\hline Moderately wasted & $1025(8.3)$ & $368(3.5)$ & $758(6.4)$ & $686(6.2)$ \\
\hline Severely wasted & $144(1.2)$ & $94(0.8)$ & $1218(10.2)$ & $1406(12.8)$ \\
\hline \multicolumn{5}{|l|}{ Media exposure } \\
\hline No & $8932(72.9)$ & $7017(62.9)$ & $6988(58.9)$ & $7375(66.9)$ \\
\hline Yes & $3328(27.1)$ & $4146(37.1)$ & $4884(41.1)$ & 3647 (33.1) \\
\hline \multicolumn{5}{|l|}{ Preceding birth interval } \\
\hline$<24$ months & $1950(15.9)$ & $2246(20.1)$ & $1963(16.5)$ & $1942(17.6)$ \\
\hline$\geq 24$ months & $10,310(84.1)$ & 8917 (79.9) & 9909 (83.5) & $9080(82.4)$ \\
\hline
\end{tabular}


Table 1 Characteristics of the study population in 2000, 2005, 2011 and 2016 Ethiopian Demographic and Health Surveys (Continued)

\begin{tabular}{|c|c|c|c|c|}
\hline Variables & EDHS $2000(n=12,260)$ & $\begin{array}{l}\text { EDHS } 2005(n=11,163) \\
\text { Weiahted frequency }(\%)\end{array}$ & $\begin{array}{l}\text { EDHS } 2011(n=11,872) \\
\text { Weiahted frequency }(\%)\end{array}$ & $\begin{array}{l}\text { EDHS } 2016(n=11,022) \\
\text { Weighted frequency (\%) }\end{array}$ \\
\hline \multicolumn{5}{|l|}{ Parity } \\
\hline $1-3$ & 5338 (43.6) & $4576(41.0)$ & $5295(44.6)$ & 4836 (43.9) \\
\hline $4-6$ & 4038 (32.9) & 3962 (35.5) & 4014 (33.8) & 3732 (33.9) \\
\hline$>6$ & 2884 (23.5) & 2625 (23.5) & 2564 (21.6) & $2454(22.2)$ \\
\hline
\end{tabular}

0.001), 40-49 years $(B=0.0008,95 \%$ CI: $0.0002,0.0014$, $p=0.04)$, multiple births $(B=-0.0003,95 \% C I:-0.0002$, $-0.0004, p=0.003)$, and births from mother who have $>$ 6 births $(B=-0.005$, 95\% CI:-0.0086, $-0.0018, p=0.02)$ were significantly contributed for the decrease in infant mortality rate over the last 16 years. Among the difference in coefficients, the difference in effects of rural residents $(B=-0.02,95 \% C I:-0.0001,-0.047, p=0.003)$, multiple births $(B=-0.0008,95 \% C I:-0.0015,-0.0018$, $p=0.012)$, health facility delivery $(B=0.004,95 \% C I$ : $0.001,0.006, p=0.023)$, and husband with secondary education or higher $(B=0.0036,95 \% C I: 0.0002,0.007$, $p=0.001$ ) were significantly contributed to the decrease in infant mortality rate over the last 16 years (Table 4 ).

\section{Determinants of infant mortality Model comparison}

The mixed-effect binary logistic regression model was the best-fitted model since it had a lower deviance value (Table 5). The ICC value was $0.13(95 \% \mathrm{CI}: 0.09,0.21)$, which indicates that about $13 \%$ of the overall variability of infant mortality was due to the between cluster variability, and the LR test was $\left(\mathrm{X}^{2}=10.44, p=0.0006\right)$ which informed us the mixed-effect binary logistic regression model (GLMM) was the best-fitted model. Moreover, the MOR-value in the null model was 1.98 (95\% CI: 1.81, 2.21), indicates that infants in high infant

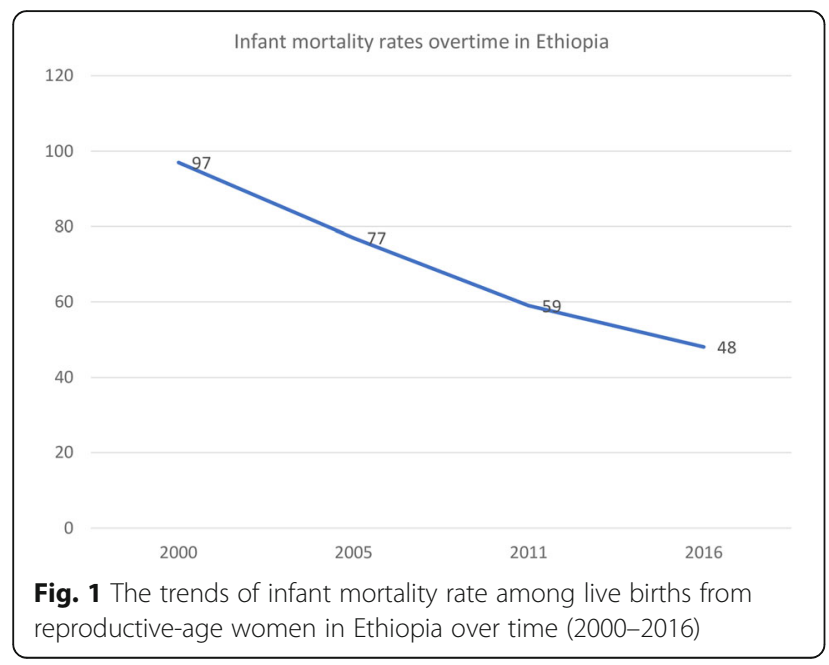

mortality clusters were a 1.98 times higher likelihood of dying in their first year of life compared to infants in low infant mortality clusters. The PCV value in the final model was 0.13 , which showed that the final model explained the variability in infant mortality by the final model was $13 \%$ (Table 6).

In the multivariable mixed-effect logistic regression model; size at birth, preceding birth interval, the number of ANC visits, maternal age, type of birth, maternal BMI, sex of the child, and parity were significant determinants factors of infant mortality. The odds of mortality among infant born to mothers aged 20-29 years, 30-39 years, and 40-49 years were decreased by $37 \%$ (95\% CI: $0.41,0.99, p=0.02$ ), $48 \%$ (95\% CI: 0.32, 0.84, $p=0.001$ ), and 49\% (95\% CI: 0.28, 0.93, $\mathrm{p}=0.02)$ compared to those born to mothers aged $<20$ years, respectively. Infants born to mothers having the preceding birth interval of < 24 months were 1.79 (95 CI: 1.46 , 2.19, $p=0.05$ ) times higher odds of death within the first year of birth than those born with a preceding birth interval of 24 months or above. The odds of infant mortality among infants who were small and large size at birth were 1.55 (95\% CI: $1.25,1.92, p=0.006)$ and 1.26 (95\% CI: 1.01, 1.57, $p=$ $0.003)$ times higher than those infants who were average size at birth, respectively. The odds of mortality among infants born from underweight women $\left(<18.5 \mathrm{~kg} / \mathrm{m}^{2}\right)$ were 1.22 (95\% CI: 1.05, 1.50, $p=0.03$ ) times higher than those born to mothers with normal BMI $\left(18.5-24.9 \mathrm{Kg} / \mathrm{m}^{2}\right)$. Births from mothers who had no ANC visits during pregnancy had a 3.14 (95\% CI: 2.11, 4.66, $p=0.001$ ) times higher likelihood of death within the first year of birth than an infant born to mothers who had > four ANC visit during pregnancy. The odds of infant death among twins were 4.25 (95\% CI: 3.01, 6.01, $p=0.0001)$ times higher than those in single births. The infant born to multiparous women having greater than 6 children had a 1.51 (95\% CI: 1.01, 2.26, $p=0.01)$ times higher odds of death than compared to an infant born to women having 1-3 births. Being male had a 1.50 (95\% CI: $1.25,1.79, p=0.007$ ) higher odds of death in the first year of life as compared to female infants (Table 7).

\section{Discussion}

The trends of infant mortality in Ethiopia was decreased from 96.9 to 48 per 1000 live births with an annual rate of reduction of $4.2 \%$. This was consistent with a study 
Infant mortality rate across regions in Ethiopia

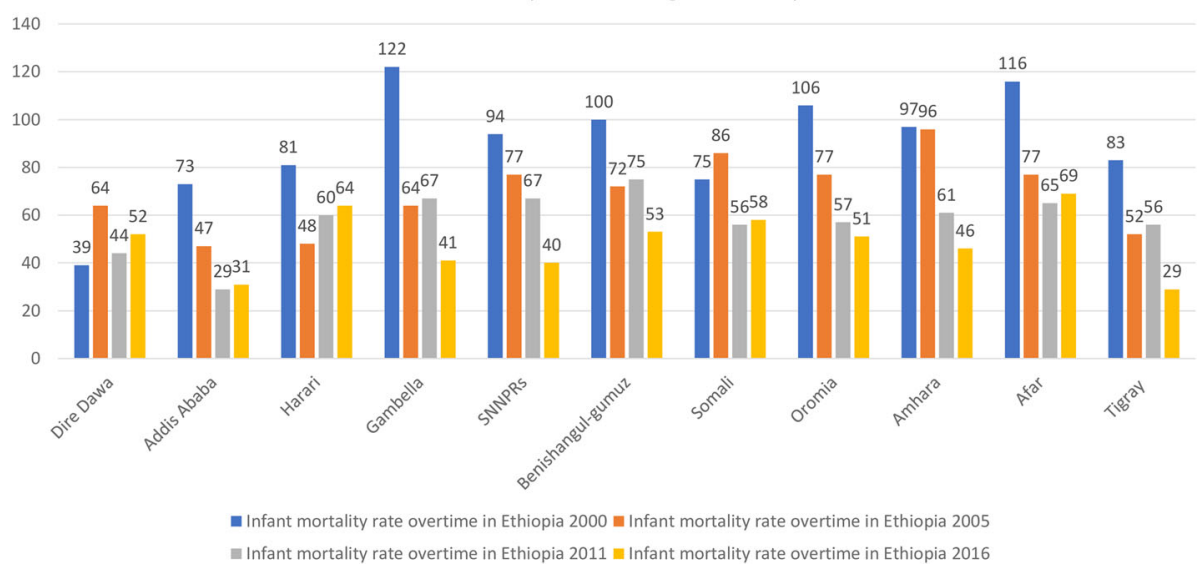

Fig. 2 The trends of infant mortality rate across region regions in Ethiopia over time (2000-2016)

reported in sub-Saharan Africa [34]. This might be because of improvement in the management of childhood illness over time [35], increased universal immunization coverage mainly targeting the commonest cause of infant mortality such as pneumonia, diarrheal diseases (Rotavirus), pertussis, and measles [36]. Besides, in the last two decades, the establishment of health extension workers plays a significant role in improving maternal and child health by providing preventive (such as a vaccine, ANC service) services and extending services to rural residents [31, 37]; possibly contributing to the significant decrease in the infant mortality rate for the last 16 years in Ethiopia.

The multivariate decomposition analysis identified the significant factors that contributed to the decrease in infant mortality rate over the last 16 years. The overall decrease in infant mortality rate over the last 16 years was associated with the difference in the composition of rural residents, maternal age, parity and type of birth, and the difference in effects of rural residents, health facility delivery, and husband education. This was supported by the study findings reported in Indonesia [32], Nicaragua [18, 38], Nigeria [18, 19], and Canada [39]. This could be because teenage pregnancies are more likely to suffer from adverse pregnancy outcomes both during and after birth including anemia, asphyxia, low birth weight, Intra-uterine Growth Reduction (IUGR), and congenital malformation; therefore the decrease in teenage pregnancy over time may contribute to the reduction of infant mortality [40]. Ethiopia proposed maternal education to increase a mother's knowledge of health care practices related to contraceptive utilization, nutrition, hygiene, and disease prevention in the reduction of infant mortality [34]. Furthermore, improved services provision at health facilities for women and the availability of skilled professionals for saving maternal and newborn lives.
In the mixed effect logistic regression analysis; size at birth, preceding birth interval, the number of ANC visits, maternal age, type of birth, sex of the child, maternal BMI, and parity were significant predictors of infant mortality. In this study, child size at birth was a significant predictor of infant mortality. The infant who was small or large size at birth were significantly associated with higher odds of infant mortality than average size infants. This was consistent with study findings in the USA [41] and Bangladesh [42]. This might be due to small size babies are commonly due to preterm birth or small for gestational age, they are prone to sepsis, hypothermia, and undernutrition and this could increase their risk of mortality. Also, low birth weight babies might have underlined medical conditions such as congenital heart diseases, down syndrome, HIV/AIDS, or other diseases and this could make them vulnerable to childhood infections like pneumonia and diarrheal diseases, consequently increase their risk of death. Regarding large size babies, commonly macrosomia is a result of maternal underlined diseases like diabetic mellites, chronic illness, and genetic causes, this could increase their risk of mortality before reaching the first year of age [43]. The shorter preceding birth interval was significantly associated with higher odds of infant mortality. This was consistent with the study findings in Malawi [44] and Zimbabwe [45]. The possible explanation might be since shorter preceding birth intervals are associated with increased risk of preterm birth, low birth weight, and IUGR for the succeeding births [46]. Besides, mothers had less time to recuperate from the previous birth, and less able to provide nourishment for the infant, this might increase the risk of infant mortality [47].

Babies born to underweight mothers $(\mathrm{BMI}<18.5 \mathrm{Kg} /$ $\mathrm{m}^{2}$ ) have higher odds of death in the first year of birth. This finding is consistent with previous study findings 
Table 2 Trends in infant mortality rate among births from reproductive-age women in the last five years before the surveys by selected characteristics in Ethiopia in 2000, 2005, 2011, and 2016 Ethiopia Demographic and Health Surveys

\begin{tabular}{lllllll}
\hline Variables & 2000 & 2005 & 2011 & 2016 & \multicolumn{3}{l}{ Point difference in infant mortality rate over time } \\
& & & $2005-2000 \quad 2011-2005 \quad 2016-2011$ & 201
\end{tabular}

\section{Place of residence}

$\begin{array}{lllllllll}\text { Urban } & 96.4 & 71.7 & 53.5 & 42.2 & -24.7 & -18.2 & -11.3 & -54.2 \\ \text { Rural } & 99.0 & 80.5 & 60.6 & 48.8 & -18.5 & -19.9 & -11.8 & -50.2\end{array}$

Religion

Orthodox

Catholic

Protestant

Muslim

Others

Age of women (in years)

$<20$
$20-29$
$30-39$
$\geq 40$

Maternal education

No education

Secondary and higher

$\begin{array}{lllll}99.6 & 82.8 & 58.6 & 44.1 & -16.8 \\ 107.5 & 39.2 & 104.5 & 57.7 & -68.3 \\ 82.7 & 73.5 & 60.4 & 43.8 & -9.2 \\ 105.7 & 83.4 & 58.9 & 53.7 & -22.3 \\ 97.0 & 50.9 & 65.9 & 38.9 & -46.1\end{array}$

$137.7 \quad 121.5$

101.5

$$
82.1
$$

93.3

83.6

68.3

117.5

89.2

57.9

47.7

$-16.2$

$-19.4$

55.1

45.4

$-15.3$

72.5

54.6

$-28.3$

$102.6 \quad 83.9$

63.2

54.5

51.1

42.2

$-18.7$

$-12.4$

32.5

40.5

$-35.4$

Husband education

No

Primary

$104.6 \quad 88.4$

55.3

93.3

74.4

40.4

51.1

$-16.2$

32.0

$-18.9$

Secondary and higher

$\begin{array}{ll}78.8 & 51.7\end{array}$

64.8

48.1

$-27.1$

Sex of household head

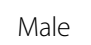

$98.4 \quad 78.9$

$101.0 \quad 87.6$

60.5

54.8

48.9

$-19.5$

42.6

$-13.4$

Maternal BMI (in $\mathrm{Kg} / \mathrm{m}^{2}$ )

$$
\begin{aligned}
& <18.5 \\
& 18.5-24.9
\end{aligned}
$$

$99.0 \quad 76.6$

97.7

120.0

77.7

68.6

56.7

55.2

$-22.4$

$-20$

64.9

46.4

$-37.9$

Number of ANC visit during pregnancy

$$
\begin{aligned}
& \text { No visit } \\
& 1-4 \text { visits }
\end{aligned}
$$

66.4

73.9

57.8

40.6

47.7

$-8.6$

$-16.6$

$>4$ visits

57.3

42.5

31.3

0.7

Size at birth

Small
Average
Large

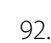

85

121.3

91.8$$
57.1
$$

56.8

$$
-0.4
$$

45.4

41.0

$-15.8$

49.9

$-40.2$

Place of delivery

Health facility

98.1

78.2

109.4

106.4

58.8

$49.8-19.9$

43.3

$-3.0$

98.9

79.8

59.5

47.4

$-19.1$ 
Table 2 Trends in infant mortality rate among births from reproductive-age women in the last five years before the surveys by selected characteristics in Ethiopia in 2000, 2005, 2011, and 2016 Ethiopia Demographic and Health Surveys (Continued)

\begin{tabular}{|c|c|c|c|c|c|c|c|c|}
\hline \multirow[t]{2}{*}{ Variables } & \multirow[t]{2}{*}{2000} & \multirow[t]{2}{*}{2005} & \multirow[t]{2}{*}{2011} & \multirow[t]{2}{*}{2016} & \multicolumn{4}{|c|}{ Point difference in infant mortality rate over time } \\
\hline & & & & & $2005-2000$ & 2011-2005 & 2016-2011 & $2016-2000$ \\
\hline Caesarean section & 77.9 & 93.0 & 74.6 & 82.8 & 15.1 & -18.4 & 8.2 & 4.9 \\
\hline \multicolumn{9}{|l|}{ Type of birth } \\
\hline Single & 90.3 & 76.6 & 55.6 & 44.0 & -13.7 & -21.0 & -11.6 & -46.3 \\
\hline Multiple & 360.9 & 260.0 & 167.3 & 196.2 & -100.9 & -92.7 & 28.9 & -164.7 \\
\hline \multicolumn{9}{|l|}{ Sex of infant } \\
\hline Male & 104.8 & 92.2 & 69.6 & 59.9 & -12.6 & -22.6 & -9.7 & -44.9 \\
\hline Female & 92.3 & 66.9 & 49.0 & 35.2 & -25.4 & -17.9 & -13.8 & -57.1 \\
\hline \multicolumn{9}{|c|}{ Ever had termination of pregnancy } \\
\hline No & 99.2 & 80.0 & 60.6 & 47.2 & -19.2 & -19.4 & -13.4 & -52.0 \\
\hline Yes & 95.7 & 79.2 & 52.1 & 57.1 & -16.0 & -27.1 & -5.0 & -38.6 \\
\hline \multicolumn{9}{|l|}{ Stunting } \\
\hline Normal & 0 & 0 & 0 & 0 & 0 & 0 & 0 & 0 \\
\hline moderately stunted & 0 & 0 & 0 & 0 & 0 & 0 & 0 & 0 \\
\hline Severely stunted & 158 & 97.5 & 260.4 & 204.0 & -60.5 & 162.9 & -56.4 & 46.0 \\
\hline \multicolumn{9}{|l|}{ Underweight } \\
\hline Normal & 0 & 0 & 0 & 0 & 0 & 0 & 0 & 0 \\
\hline Moderately underweight & 0 & 0 & 0 & 0 & 0 & 0 & 0 & 0 \\
\hline Severely underweight & 153 & 94.0 & 359.9 & 281.0 & -69 & 265.9 & -78.9 & 128 \\
\hline \multicolumn{9}{|l|}{ Wasting } \\
\hline Normal & 0 & 0 & 0 & 0 & 0 & 0 & 0 & 0 \\
\hline Moderately wasted & 0 & 0 & 0 & 0 & 0 & 0 & 0 & 0 \\
\hline Severely wasted & 109 & 83.0 & 581.5 & 376.7 & -26 & 498.5 & -204.8 & 267.7 \\
\hline \multicolumn{9}{|l|}{ Media exposure } \\
\hline No & 102.1 & 80.6 & 59.1 & 42.9 & -21.5 & -21.5 & -16.2 & -60.2 \\
\hline Yes & 89.6 & 78.8 & 60.1 & 58.5 & -10.8 & -18.7 & -1.6 & -31.1 \\
\hline \multicolumn{9}{|l|}{ Preceding birth interval } \\
\hline$<24$ months & 150.4 & 131.5 & 94.1 & 83.6 & -18.9 & -37.4 & -10.5 & -66.8 \\
\hline$\geq 24$ months & 88.9 & 66.9 & 52.9 & 40.4 & -22.0 & -14.0 & -12.5 & -48.5 \\
\hline \multicolumn{9}{|l|}{ Parity } \\
\hline $1-3$ & 99.1 & 77.6 & 52.8 & 43.9 & -21.5 & -24.8 & -8.9 & -55.2 \\
\hline $4-6$ & 87.5 & 72.7 & 64.2 & 48.3 & -14.8 & -8.5 & -15.9 & -39.4 \\
\hline$>6$ & 113.7 & 94.7 & 91.0 & 80.9 & -19.0 & -3.7 & -10.2 & -34.8 \\
\hline
\end{tabular}

Table 3 The overall Logit based multivariate decomposition analysis of infant mortality in Ethiopia, 2000-2016

\begin{tabular}{llll}
\hline Infant mortality & Coef. & [95\% Conf. Interval] & Pct. \\
\hline E & -0.008 & $-0.016-0.0007$ & $18.1^{\mathrm{a}}$ \\
$\mathrm{C}$ & -0.037 & $-0.047-0.027$ & $81.9^{\mathrm{a}}$ \\
$\mathrm{R}$ & -0.045 & $-0.052-0.038$ & \\
\hline
\end{tabular}

${ }^{\mathrm{a}} E$ Endowment, $C$ Coefficient, $R$ Residuals, Coef Coefficient, Pct Percent
[48]; malnourished mothers have an increased risk of poor pregnancy outcomes including obstructed labor, premature delivery, and low-birth-weight babies [49]. Therefore, an infant born to a malnourished mother is more prone to malnutrition and childhood illnesses like diarrheal diseases and respiratory diseases which are the leading cause of child mortality [50]. In this study, parity and twin birth were significant predictors of infant mortality; an infant born to multiparous women who have greater than 6 births, and twin births, had higher odds of death before reaching the first year of birth. This was 
Table 4 The detailed Logit based multivariate decomposition analysis of infant mortality in Ethiopia, 2000-2016

\begin{tabular}{|c|c|c|c|c|}
\hline \multirow[t]{2}{*}{ Infant death } & \multicolumn{2}{|l|}{ Difference due to characteristics(E) } & \multicolumn{2}{|l|}{ Difference due to coefficient (C) } \\
\hline & Coef. with $p$-value & Pct. & Coef. with $p$-value & Pct. \\
\hline \multicolumn{5}{|l|}{ Residence } \\
\hline Urban & 0 & & 0 & \\
\hline Rural & $-0.0006[-0.0009,-0.0004]^{*}, 0.03$ & -1.08 & $-0.02[-0.0001,-0.047]^{* *}, 0.003$ & -52.1 \\
\hline \multicolumn{5}{|l|}{ Age of women } \\
\hline$<20$ & 0 & & 0 & \\
\hline $20-29$ & $-0.0001[-0.0003,0.0007], 0.23$ & 0.29 & $0.005[-0.013,0.022], 0.12$ & -10.4 \\
\hline $30-39$ & $-0.0007[-0.001,-0.0002]^{* *}, 0.001$ & 1.4 & $0.004[-0.01,0.018], 0.06$ & -8.3 \\
\hline$\geq 40$ & $0.0008[0.0002,0.0014]^{*}, 0.04$ & -1.8 & $-0.001[-0.006,0.004], 0.21$ & 2.4 \\
\hline \multicolumn{5}{|l|}{ Maternal education } \\
\hline No education & 0 & & 0 & \\
\hline Primary & $-0.0006[-0.002,0.0008], 0.07$ & 1.3 & $-0.0002[-0.003,0.003], 0.42$ & 0.05 \\
\hline Secondary and higher & $-0.0003[-0.001,0.0004], 0.31$ & 0.71 & $0.0017[-0.001,0.004], 0.34$ & 1.9 \\
\hline \multicolumn{5}{|l|}{ Type of birth } \\
\hline Single & 0 & & 0 & \\
\hline Multiple & $-0.0003[-0.0002,-0.0004]^{* *}, 0.003$ & -0.69 & $-0.0008[-0.0015,0.0018]^{*}, 0.012$ & -1.9 \\
\hline \multicolumn{5}{|l|}{ Place of delivery } \\
\hline Home & 0 & & 0 & \\
\hline Health facility & $-0.002[-0.005,0.0006], 0.08$ & 4.4 & $0.004[0.001,0.006]^{*}, 0.023$ & -7.9 \\
\hline \multicolumn{5}{|l|}{ Parity } \\
\hline $1-3$ & 0 & & 0 & \\
\hline $4-6$ & $0.00005[-0.0003,0.0003], 0.09$ & -0.3 & $0.005[-0.002,0.011], 0.07$ & -10.1 \\
\hline$>6$ & $-0.005[-0.0086,-0.0018]^{*}, 0.02$ & 11.5 & $0.001[-0.002,0.004], 0.09$ & -16.4 \\
\hline \multicolumn{5}{|c|}{ Ever had termination of pregnancy } \\
\hline No & 0 & & 0 & \\
\hline Yes & $-0.0005[-0.0014,0.0004], 0.071$ & 1.07 & $0.0014[-0.0022,0.005], 0.51$ & -3.06 \\
\hline \multicolumn{5}{|c|}{ Body mass index of women $\left(\mathrm{kg} / \mathrm{m}^{2}\right)$} \\
\hline$<18.5$ & 0 & & 0 & \\
\hline $18.5-24.9$ & $0.0006[-0.0002,0.001], 0.4$ & -1.36 & $-0.014[-0.026,0.0001], 0.21$ & 31.4 \\
\hline$\geq 25$ & $-0.0014[-0.002,0.0003], 0.37$ & 2.33 & $-0.0014[-0.003,0.0001], 0.17$ & 3.06 \\
\hline \multicolumn{5}{|l|}{ Husband education } \\
\hline no education & 0 & & 0 & \\
\hline Primary & $0.0003[-0.0017,0.0024], 0.08$ & -0.74 & $0.0005[-0.0055,0.0065], 0.47$ & -1.12 \\
\hline Secondary & $0.0008[-0.0035,0.0052], 0.13$ & -1.8 & $0.0036[0.0002,0.007]^{* *}, 0.001$ & -8.03 \\
\hline \multicolumn{5}{|l|}{ Media exposure } \\
\hline No & 0 & & 0 & \\
\hline Yes & $0.0001[-0.0007,0.0003], 0.19$ & -0.28 & $0.0039[-0.0018,0.0097], 0.07$ & -8.8 \\
\hline Constant & & & $-0.071[-0.119,-0.023], 0.3$ & 157.14 \\
\hline
\end{tabular}

Table 5 Model comparison between standard logistic regression and mixed-effects logistic regression

\begin{tabular}{llll}
\hline Model comparison & AIC & BIC & Deviance \\
\hline Logistic regression model & 4033.79 & 4221.50 & 3987.80 \\
Mixed effect logistic regression model & 4026.93 & 4201.47 & 3978.94 \\
\hline
\end{tabular}

AIC Akaike Information Criteria, BIC Bayesian Information Criteria consistent with studies reported in Pristina [51] and Australia [52]. The possible reason could be due to multiparous women and twins are related to an increased rate of adverse perinatal outcomes, such as premature birth and low birth weight [53]. The higher mortality rate among multiple births compared with single births 
Table 6 Random effect parameters

\begin{tabular}{lll}
\hline Random effect parameters & Null model & Full model \\
\hline Cluster variance & $0.52(0.39,0.70)$ & $0.45(0.23,0.91)$ \\
ICC & $0.1(0.04,0.13)$ & $0.06(0.015,0.20)$ \\
MOR & $1.98(1.81,2.21)$ & $1.89(1.58,2.48)$ \\
PCV & Ref. & 0.13 \\
\hline
\end{tabular}

ICC Intra-class Correlation Coefficient, MOR Median Odds Ratio, $P C V$ Proportional Change in Variance

could be because twins are more likely to be born prematurely, higher risk of malnutrition, and more likely to be of lower birth weight than single infants this could increase the risk of death within 1 year of birth [54].

In our study, ANC was a significant predictor of infant mortality. The odds of infant mortality among women who had no ANC visit during pregnancy was higher than those who have ANC checkup. This was supported by the study findings in India [55] and Nepal [56], it could be due to reason that ANC visit is an entry point for the other maternal health services, and births from mother who had no ANC visit are not aware of danger signs of pregnancy and underlying medical conditions that could lead to low birth weight, prematurity, congenital anomalies as compared to women who had ANC visit [57]. The odds of infant mortality among births mothers aged $\geq 20$ years were lower than births from mothers aged less than 20 years. It was consistent with prior studies [58], the possible explanation could be due to the reason that teenagers have biological immaturity and nutrition which could increase the risk of infant mortality [59]. Besides, teenagers are less likely to use maternal health care services such as ANC, institutional delivery, $\mathrm{PNC}$, and routine immunization this could increase the odds of infant mortality [60]. Male infants were significantly associated with higher odds of infant mortality, which is supported by previous studies [61,62]. The possible explanation for this difference might be due to sex differences in genetic and biological makeup, with boys being biologically weaker and more susceptible to diseases and premature death [63].

\section{Strength and limitations}

This study had several strengths. First, the study was based on nationally representative large datasets, and thus it had adequate statistical power. Second, the estimates of the study were done after the data were weighted for the probability sampling and nonresponse, to make it representative at national and regional levels: therefore, it can be generalized to all births from reproductive-age women in Ethiopia. Third, multivariate decomposition analysis was applied to understand the factors that significantly contributed to the decrease in infant mortality over time. Limitations included that variables were not consistently collected in all EDHS surveys; the wealth index was not collected in EDHS 2000 even if it was planned for collection, thus this variable was not used for the decomposition analysis. In addition, important variables such as underlying medical conditions such as pneumonia, meningitis, birth asphyxia, congenital heart diseases, diarrheal diseases, sepsis, HIV/AIDS, congenital infections were not considered in the model as these variables didn't found in the EDHS. Furthermore, the EDHS survey did not incorporate community-level variables like community norm, culture, and beliefs, and medical factors rather it relied on mothers or caregivers report and might have the possibility of social desirability and recall bias since infant mortality is not socially acceptable though CSA claims that strong effort was made to minimize it mainly through extensive training of data collectors, recruiting experienced data collectors and supervisors this might underestimate our finding.

\section{Policy implications of this study}

Infant mortality has been considered as the crucial indicator of the quality of the health care delivery system and progress of Ethiopia. Though the infant mortality rate in Ethiopia showed a significant reduction over time, still we are expected to have double progress to achieve the ENAP plan. To keep this progress maternal and child health programs should focus on promoting ANC visits, and adequate birth spacing as these factors are amenable to change. Moreover, health care providers should give special attention to abnormal weight babies, multiple births, and male births to reduce the incidence of infant mortality in the country.

\section{Conclusions}

The infant mortality rate has shown a dramatic decrease over the last 16 years in Ethiopia. The multivariate decomposition analysis revealed that about $18.1 \%$ of the overall decrease in infant mortality was attributable to the difference in endowment (the composition of respondents) in terms of residence, maternal age, type of birth, and parity across the surveys whereas the remaining $81.9 \%$ was due to the difference in the effect of residence, parity, health facility delivery and husband education over the surveys. These findings highlight that the governmental and non-governmental organizations should scale up health facility delivery and give special attention to twin births, multiparous women, rural dwellers to 
Table 7 The bi-variable and multivariable mixed-effect logistic regression analysis of determinants of infant mortality among births from reproductive-age women in Ethiopia, 2016

\begin{tabular}{|c|c|c|c|c|c|c|}
\hline \multirow[t]{2}{*}{ Variables } & \multicolumn{2}{|c|}{ Infant status } & \multirow{2}{*}{$\begin{array}{l}\text { Crude Odds } \\
\text { Ratio (COR) } \\
\text { with } 95 \% \mathrm{Cl}\end{array}$} & \multirow{2}{*}{$\begin{array}{l}p- \\
\text { value }\end{array}$} & \multirow{2}{*}{$\begin{array}{l}\text { Adjusted Odds } \\
\text { Ratio (AOR) } \\
\text { with } 95 \% \mathrm{Cl}\end{array}$} & \multirow{2}{*}{$\begin{array}{l}p \text { - } \\
\text { value }\end{array}$} \\
\hline & Alive & Died & & & & \\
\hline \multicolumn{7}{|l|}{ Residence } \\
\hline Urban & 1913 & 61 & 1 & & 1 & \\
\hline Rural & 8187 & 480 & $1.85[1.39,2.48]$ & 0.001 & $1.42[0.98,2.06]$ & 0.19 \\
\hline \multicolumn{7}{|l|}{ Sex of household head } \\
\hline Male & 7944 & 439 & 1 & & 1 & \\
\hline Female & 2156 & 102 & $0.85[0.68,1.07]$ & 0.16 & $0.89[0.70,1.12]$ & 0.68 \\
\hline \multicolumn{7}{|l|}{ Wealth status } \\
\hline Poor & 5441 & 334 & $1.42[1.14,1.75]$ & 0.002 & $0.84[0.65,1.09]$ & 0.58 \\
\hline Middle & 1399 & 67 & $1.12[0.82,1.51]$ & 0.51 & $0.81[0.58,1.13]$ & 0.19 \\
\hline Rich & 3260 & 140 & 1 & & 1 & \\
\hline \multicolumn{7}{|l|}{ Parity } \\
\hline $1-3$ & 6003 & 291 & 1 & & 1 & \\
\hline $4-6$ & 3457 & 193 & $1.14[0.95,1.39]$ & 0.16 & $1.01[0.79,1.29]$ & 0.93 \\
\hline$>6$ & 640 & 57 & $1.82[1.34,2.47]$ & 0.0001 & $1.51[1.01,2.26]^{*}$ & 0.01 \\
\hline \multicolumn{7}{|l|}{ Maternal BMI $\left(\mathrm{Kg} / \mathrm{m}^{2}\right)$} \\
\hline$<18.5$ & 2306 & 153 & $1.27[1.04,1.56]$ & 0.001 & $1.22[1.05,1.50]^{*}$ & 0.03 \\
\hline$\geq 25$ & 1306 & 50 & $0.73[0.54,0.99]$ & 0.05 & $0.78[0.57,1.08]$ & 0.44 \\
\hline $18.5-24.9$ & 6488 & 338 & 1 & & 1 & \\
\hline \multicolumn{7}{|c|}{ Covered by health insurance } \\
\hline Yes & 316 & 5 & 1 & & 1 & \\
\hline No & 9784 & 536 & $3.28[1.33,8.06]$ & 0.01 & $2.49[0.99,6.18]$ & 0.25 \\
\hline \multicolumn{7}{|l|}{ Sex of the child } \\
\hline Male & 5157 & 326 & $1.44[1.21,1.72]$ & 0.001 & $1.50[1.25,1.79]^{* *}$ & 0.007 \\
\hline Female & 4943 & 215 & 1 & & 1 & \\
\hline \multicolumn{7}{|l|}{ Type of birth } \\
\hline Single & 9875 & 488 & 1 & & 1 & \\
\hline Multiple & 223 & 53 & $5.01[3.60,6.97]$ & 0.0001 & $4.25[3.01,6.01]^{* *}$ & 0.0001 \\
\hline \multicolumn{7}{|l|}{ Place of delivery } \\
\hline Health facility & 3345 & 141 & 1 & & 1 & \\
\hline Home & 6755 & 400 & $1.37[1.11,1.68]$ & 0.03 & $0.78[0.61,1.05]$ & 0.83 \\
\hline \multicolumn{7}{|l|}{ Maternal age (in years) } \\
\hline$<20$ & 379 & 25 & 1 & & 1 & \\
\hline $20-29$ & 5054 & 278 & $0.84[0.55,1.29]$ & 0.21 & $0.63[0.41,0.99]^{*}$ & 0.02 \\
\hline $30-39$ & 3864 & 193 & $0.76[0.49,1.18]$ & 0.19 & $0.52[0.32,0.84]^{* *}$ & 0.001 \\
\hline$\geq 40$ & 803 & 45 & $0.85[0.51,1.43]$ & 0.2 & $0.51[0.28,0.93]^{*}$ & 0.02 \\
\hline \multicolumn{7}{|l|}{ Maternal education } \\
\hline No & 6460 & 378 & $1.57[1.11,2.22]$ & 0.01 & $0.96[0.64,1.44]$ & 0.73 \\
\hline Primary & 2554 & 124 & $1.33[0.92,1.94]$ & 0.13 & $1.01[0.67,1.51]$ & 0.61 \\
\hline Secondary and higher & 1086 & 39 & 1 & & 1 & \\
\hline \multicolumn{7}{|c|}{ Number of ANC visit during pregnancy } \\
\hline No & 5506 & 423 & $3.50[2.42,5.07]$ & 0.0001 & $3.14[2.11,4.66]^{*}$ & 0.001 \\
\hline $1-4$ & 3146 & 86 & $1.23[0.81,1.86]$ & 0.32 & $1.14[0.75,1.74]$ & 0.65 \\
\hline
\end{tabular}


Table 7 The bi-variable and multivariable mixed-effect logistic regression analysis of determinants of infant mortality among births from reproductive-age women in Ethiopia, 2016 (Continued)

\begin{tabular}{|c|c|c|c|c|c|c|}
\hline \multirow[t]{2}{*}{ Variables } & \multicolumn{2}{|c|}{ Infant status } & \multirow{2}{*}{$\begin{array}{l}\text { Crude Odds } \\
\text { Ratio (COR) } \\
\text { with } 95 \% \mathrm{Cl}\end{array}$} & \multirow{2}{*}{$\begin{array}{l}p \text { - } \\
\text { value }\end{array}$} & \multirow{2}{*}{$\begin{array}{l}\text { Adjusted Odds } \\
\text { Ratio (AOR) } \\
\text { with } 95 \% \mathrm{Cl}\end{array}$} & \multirow{2}{*}{$\begin{array}{l}p \text { - } \\
\text { value }\end{array}$} \\
\hline & Alive & Died & & & & \\
\hline$>4$ & 1452 & 32 & 1 & & 1 & \\
\hline \multicolumn{7}{|c|}{ Preceding birth interval } \\
\hline$<24$ months & 1943 & 175 & $1.97[1.63,2.38]$ & 0.001 & $1.79[1.46,2.19]^{*}$ & 0.05 \\
\hline$\geq 24$ months & 8157 & 366 & 1 & & 1 & \\
\hline \multicolumn{7}{|l|}{ Size at birth } \\
\hline Average & 3051 & 163 & 1 & & 1 & \\
\hline Small & 2811 & 197 & $1.64[1.32,2.02]$ & 0.0001 & $1.55[1.25,1.92]^{* *}$ & 0.003 \\
\hline Large & 4238 & 181 & $1.24[0.99,1.55]$ & 0.015 & $1.26[1.01,1.57]^{* *}$ & 0.006 \\
\hline
\end{tabular}

"ANC Antenatal Care Utilization, AOR Adjusted Odds Ratio, BMI Body Mass Index, Cl Confidence Interval, COR Crude Odds Ratio, * $p$-value $<0.05$, ${ }^{* *} p$-value $<0.01$

further reduce the infant mortality rate in Ethiopia. Besides; birth interval, maternal BMI, size at birth, parity, maternal age, type of birth, sex of the child, and ANC visit were significantly associated with infant mortality. Therefore, it could help the policymakers and health planners to focus on designing prevention programs and health care delivery, thus allocating public health resources for further reducing infant mortality.

\section{Abbreviations}

ANC: Antenatal Care; AOR: Adjusted Odds Ratio; COR: Crude Odds Ratio, CSA=Central Statistical Agency; DHS: Demographic health survey; EAs: Enumeration areas; EDHS: Ethiopian demographic and health survey; GIS: Geographic Information System; ICC: Intra-cluster Correlation Coefficient; IUGR: Intra uterine growth restriction; LLR: Log likelihood ratio; LR: Likelihood ratio; MDG: Millennium Development Goals; RR: Relative risk; SNNP: Southern Nations and Nationalities of People

\section{Acknowledgments}

We would like to thank the measure DHS program for providing the data set.

\section{Authors' contributions}

Conceptualization: GAT, DAA, WSS and MGW, Data curation GAT, DAA, WSS, and MGW. Investigation: GAT, DAA, WSS and MGW, Methodology: GAT, DAA, WSS and MGW, Software: GAT, DAA, WSS and MGW, Validation: GAT, DAA, WSS and MGW, Writing: GAT, DAA, WSS and MGW, Writing - review, and editing: GAT, DAA, WSS, and MGW. All the authors read and approve the manuscript.

\section{Funding}

No funding was obtained for this study.

\section{Availability of data and materials}

Data is available online and you can access it from www.measuredhs.com.

\section{Declarations}

\section{Ethics approval and consent to participate}

The EDHS data is available to the general public by request in different formats from the Measure DHS website http://www.measuredhs.com. We submitted a request to the Measure DHS by briefly stating the objectives of this analysis and thereafter received permission to download the maternal and children's dataset in STATA format.
Consent for publication

Not applicable.

\section{Competing interests}

Authors declare that they have no conflict of interest.

\section{Author details}

'Department of Epidemiology and Biostatistics, institute of public health, college of medicine and health science, University of Gondar, Gondar, Ethiopia. ${ }^{2}$ Department of Human Anatomy, School of Medicine, College of Medicine and Health Science, University of Gondar, Gondar, Ethiopia.

Received: 5 October 2020 Accepted: 27 April 2021

Published online: 05 May 2021

\section{References}

1. Mortality NCtPI. Death before life: the tragedy of infant Mortality: the report of the National Commission to prevent infant Mortality: the commission; 1988.

2. UNICEF W. Levels and trends in child mortality: report 2011. Estimates developed by the UN Inter-agency Group for child mortality estimation New York: United Nation's Children Fund 2011.

3. WHO. Global Health Observatory (GHO) data 2017.

4. Sartorius BK, Sartorius K. Global infant mortality trends and attributable determinants-an ecological study using data from 192 countries for the period 1990-2011. Popul Health Metrics. 2014;12(1):29. https://doi.org/10.11 86/s12963-014-0029-6.

5. Rutstein SO. Factors associated with trends in infant and child mortality in developing countries during the 1990s. Bull World Health Organ. 2000; 78(10):1256-70.

6. ICF CSACEa. Ethiopia Demographic and Health Survey 2016. Addis Ababa and Rockville: CSA and ICF; 2016.

7. de Oliveira CM, do Bonfim CV, Guimarães MJB, Frias PG, Medeiros ZM. Infant mortality: temporal trend and contribution of death surveillance. Acta Paul Enferm. 2016;29(3):282-90. https://doi.org/10.1590/1982-0194201600040.

8. Deogaonkar M. Socio-economic inequality and its effect on healthcare delivery in India: inequality and healthcare. Electron J Soc. 2004;11.

9. Rajaratnam JK, Marcus JR, Flaxman AD, Wang H, Levin-Rector A, Dwyer L, et al. Neonatal, postneonatal, childhood, and under-5 mortality for 187 countries, 1970-2010: a systematic analysis of progress towards millennium development goal 4. Lancet. 2010;375(9730):1988-2008. https://doi.org/10.1 016/S0140-6736(10)60703-9.

10. Tomashek KM, Qin C, Hsia J, lyasu S, Barfield WD, Flowers LM. Infant mortality trends and differences between American Indian/Alaska native infants and white infants in the United States, 1989-1991 and 1998-2000. Am J Public Health. 2006;96(12):2222-7. https://doi.org/10.2105/AJPH.2004. 053744

11. Ruducha J, Mann C, Singh NS, Gemebo TD, Tessema NS, Baschieri A, et al. How Ethiopia achieved millennium development goal 4 through multisectoral interventions: a countdown to 2015 case study. Lancet Glob 
Health. 2017;5(11):e1142-e51. https://doi.org/10.1016/S2214-109X(17)303315.

12. Assefa Y, Van Damme W, Williams OD, Hill PS. Successes and challenges of the millennium development goals in Ethiopia: lessons for the sustainable development goals. BMJ Glob Health. 2017;2(2):e000318. https://doi.org/1 0.1136/bmjgh-2017-000318.

13. CSA I. Ethiopia demographic and health survey 2011, vol. 430. Addis Ababa and Calverton: Central Statistical Agency and ICF International; 2012.

14. 2016. CSACEal. Ethiopia Demographic and Health Survey 2016. Addis Ababa and Rockville: CSA and ICF; 2016.

15. Macro. CSAEaO. Ethiopia Demographic and Health Survey 2000, vol. 2001. Addis Ababa and Calverton: Central Statistical Authority and ORC Macro; 2001. Report No

16. Finlay JE, Özaltin E, Canning D. The association of maternal age with infant mortality, child anthropometric failure, diarrhoea and anaemia for first births: evidence from 55 low-and middle-income countries. BMJ Open. 2011;1(2):e000226. https://doi.org/10.1136/bmjopen-2011-000226.

17. Friede A, Baldwin W, Rhodes PH, Buehler JW, Strauss LT. Older maternal age and infant mortality in the United States. Obstet Gynecol. 1988;72(2):152-7.

18. Peña R, Wall S, Persson L-A. The effect of poverty, social inequity, and maternal education on infant mortality in Nicaraqua, 1988-1993. Am J Public Health. 2000;90(1):64-9. https://doi.org/10.2105/ajph.90.1.64.

19. Caldwell J, McDonald P. Influence of maternal education on infant and child mortality: levels and causes. Health Policy Educ. 1982;2(3-4):251-67. https:// doi.org/10.1016/0165-2281(82)90012-1.

20. Stockwell EG. Infant mortality and socio-economic status: a changing relationship. Milbank Mem Fund Q. 1962;40(1):101-11. https://doi.org/10.23 07/3348613.

21. Dube L, Taha M, Asefa H. Determinants of infant mortality in community of Gilgel gibe field research center, Southwest Ethiopia: a matched case control study. BMC Public Health. 2013;13(1):401. https:/doi.org/10.1186/1471-2458-13-401.

22. Slinkard SA, Pharr JR, Bruno T, Patel D, Ogidi A, Obiefune M, et al, Determinants of infant Mortality in Southeast Nigeria: results from the healthy beginning initiative, 2013-2014. Int J MCH AIDS. 2018;7(1):1-8. https://doi.org/10.21106/ijma.229.

23. Kozuki N, Lee AC, Silveira MF, Sania A, Vogel JP, Adair L, et al. The associations of parity and maternal age with small-for-gestational-age, preterm, and neonatal and infant mortality: a meta-analysis. BMC Public Health. 2013;13(S3):S2. https://doi.org/10.1186/1471-2458-13-S3-S2.

24. Ayeni O, Oduntan SO. The effects of sex, birthweight, birth order and maternal age on infant mortality in a Nigerian community. Ann Hum Biol. 1978;5(4):353-8. https://doi.org/10.1080/03014467800002991.

25. Stanley WA, Huber LRB, Laditka SB, Racine EF. Association of type of birth attendant and place of delivery on infant mortality in sub-Saharan Africa. Afr Health Sci. 2016;16(1):1-9. https://doi.org/10.4314/ahs.v16i1.1.

26. Fawzi UW, Herrera MG, Spiegelman DL, El Amin A, Nestel P, Mohamed KA. A prospective study of malnutrition in relation to child mortality in the Sudan. Am J Clin Nutr. 1997;65(4):1062-9. https://doi.org/10.1093/ajcn/65.4.1062.

27. Bawah AA, Phillips JF, Adjuik M, Vaughan-Smith M, Macleod B, Binka FN. The impact of immunization on the association between poverty and child survival: evidence from Kassena-Nankana District of northern Ghana. Scand J Public Health. 2010;38(1):95-103. https://doi.org/10.1177/1403494809352532.

28. Clarke LL, Coward RT. A multivariate assessment of the effects of residence on infant mortality. J Rural Health. 1991;7(3):246-65. https://doi.org/10.1111/ j.1748-0361.1991.tb00726.x.

29. Kumar PP, File G. Infant and child mortality in Ethiopia: a statistical analysis approach. Ethiop J Educ Sci. 2010;5(2).

30. Weldearegawi B, Melaku YA, Abera SF, Ashebir Y, Haile F, Mulugeta A, et al. Infant mortality and causes of infant deaths in rural Ethiopia: a populationbased cohort of 3684 births. BMC Public Health. 2015;15(1):770. https://doi. org/10.1186/s12889-015-2090-x.

31. Alebachew A, Hatt L, Kukla M. Monitoring and evaluating progress towards universal health coverage in Ethiopia. PLoS Med. 2014;11(9):e1001696. https://doi.org/10.1371/journal.pmed.1001696.

32. Soejoenoes A. Tenage pregnancy. Indonesian J Obstet Gynecol. 2017:128-9. https://doi.org/10.32771/inajog.v5i3.533.

33. Sullivan JM, Rutstein SO, Bicego GT. Infant and child mortality: macro international Calverton, Maryland; 1994.

34. Akachi Y, Canning D. Health trends in sub-Saharan Africa: conflicting evidence from infant mortality rates and adult heights. Econ Hum Biol. 2010;8(2):273-88. https://doi.org/10.1016/j.ehb.2010.05.015.
35. Miller NP, Amouzou A, Tafesse M, Hazel E, Legesse H, Degefie T, et al. Integrated community case management of childhood illness in Ethiopia: implementation strength and quality of care. Am J Trop Med Hyg. 2014; 91(2):424-34. https://doi.org/10.4269/ajtmh.13-0751.

36. Kiros G-E, White MJ. Migration, community context, and child immunization in Ethiopia. Soc Sci Med. 2004;59(12):2603-16. https://doi.org/10.1016/j. socscimed.2004.04.009.

37. Gove S. Integrated management of childhood illness by outpatient health workers: technical basis and overview. The WHO Working Group on Guidelines for Integrated Management of the Sick Child. Bull World Health Organ. 1997;75(Suppl 1):7.

38. Peña R, Liljestrand J, Zelaya E, Persson L-A. Fertility and infant mortality trends in Nicaragua 1964-1993. The role of women's education. J Epidemiol Community Health. 1999;53(3):132-7. https://doi.org/10.1136/jech.53.3.132.

39. Joseph K, Kramer MS. Recent trends in infant mortality rates and proportions of low-birth-weight live births in Canada. Cmaj. 1997;157(5): $535-41$.

40. Molla T. Higher education policy reform in Ethiopia: the representation of the problem of gender inequality. High Educ Policy. 2013;26(2):193-215. https://doi.org/10.1057/hep.2012.25.

41. Shi L, Macinko J, Starfield B, Xu J, Regan J, Politzer R, et al. Primary care, infant mortality, and low birth weight in the states of the USA. J Epidemiol Community Health. 2004;58(5):374-80. https://doi.org/10.1136/jech.2003.013 078.

42. Yasmin $\mathrm{S}$, Osrin D, Paul E, Costello A. Neonatal mortality of low-birth-weight infants in Bangladesh. Bull World Health Organ. 2001;79(7):608-14.

43. Black RE, Allen LH, Bhutta ZA, Caulfield LE, De Onis M, Ezzati M, et al. Maternal and child undernutrition: global and regional exposures and health consequences. Lancet. 2008;371(9608):243-60. https://doi.org/10.101 6/S0140-6736(07)61690-0.

44. Madise NJ, Diamond I. Determinants of infant mortality in Malawi: an analysis to control for death clustering within families. J Biosoc Sci. 1995; 27(1):95-106. https://doi.org/10.1017/S0021932000007033.

45. Kembo J, Van Ginneken JK. Determinants of infant and child mortality in Zimbabwe: results of multivariate hazard analysis. Demogr Res. 2009;21:36784. https://doi.org/10.4054/DemRes.2009.21.13.

46. McDONALD SD, Han Z, Mulla S, Murphy KE, Beyene J, Ohlsson A. Preterm birth and low birth weight among in vitro fertilization singletons: a systematic review and meta-analyses. Eur J Obstet Gynecol Reprod Biol. 2009;146(2):138-48. https://doi.org/10.1016/j.ejogrb.2009.05.035.

47. Curtis SL, Diamond I, MCDonald JW. Birth interval and family effects on postneonatal mortality in Brazil. Demography. 1993;30(1):33-43. https://doi. org/10.2307/2061861.

48. Edwards LE, Alton IR, Barrada MI, Hakanson EY. Pregnancy in the underweight woman: course, outcome, and growth patterns of the infant. Am J Obstet Gynecol. 1979;135(3):297-302. https://doi.org/10.1016/0002-93 78(79)90693-8.

49. Konje JC, Ladipo OA. Nutrition and obstructed labor. Am J Clin Nutr. 2000; 72(1):291S-7S. https://doi.org/10.1093/ajcn/72.1.291S.

50. Foster SO. Immunizable and respiratory diseases and child mortality. Popul Dev Rev. 1984;10:119-40. https://doi.org/10.2307/2807958.

51. Andrejevic A, Cvetkovic S, Vitosevic Z, Andrejevic L, Relic G. Multiparity, perinatal morbidity and mortality. Clin Exp Obstet Gynecol. 2011;38(1):71-5.

52. Bai J, Wong FW, Bauman A, Mohsin M. Parity and pregnancy outcomes. Am J Obstet Gynecol. 2002;186(2):274-8. https://doi.org/10.1067/mob.2002.11 9639 .

53. Boulet SL, Schieve LA, Nannini A, Ferre C, Devine O, Cohen B, et al. Perinatal outcomes of twin births conceived using assisted reproduction technology: a population-based study. Hum Reprod. 2008;23(8):1941-8. https://doi.org/1 0.1093/humrep/den169.

54. Suri K, Bhandari V, Lerer T, Rosenkrantz TS, Hussain N. Morbidity and mortality of preterm twins and higher-order multiple births. J Perinatol. 2001;21(5):293-9. https://doi.org/10.1038/sj.jp.7200492.

55. Sahu D, Nair S, Singh L, Gulati B, Pandey A. Levels, trends \& predictors of infant \& child mortality among scheduled tribes in rural India. Indian J Med Res. 2015;141(5):709-19. https://doi.org/10.4103/0971-5916.159593.

56. Katz J, West KP Jr, Khatry SK, Christian P, LeClerq SC, Pradhan EK, et al. Risk factors for early infant mortality in Sarlahi district, Nepal. Bull World Health Organ. 2003;81(10):717-25.

57. Pembe AB, Carlstedt A, Urassa DP, Lindmark G, Nyström L, Darj E. Quality of antenatal care in rural Tanzania: counselling on pregnancy danger signs. 
BMC Pregnancy Childbirth. 2010;10(1):35. https://doi.org/10.1186/1471-23 93-10-35.

58. Olausson PO, Cnattingius S, Haglund B. Teenage pregnancies and risk of late fetal death and infant mortality. BJOG Int J Obstet Gynaecol. 1999; 106(2):116-21. https://doi.org/10.1111/j.1471-0528.1999.tb08210.x.

59. Chen X-K, Wen SW, Fleming N, Demissie K, Rhoads GG, Walker M. Teenage pregnancy and adverse birth outcomes: a large population based retrospective cohort study. Int J Epidemiol. 2007;36(2):368-73. https://doi. org/10.1093/ije/dyl284.

60. Barber S. Does the quality of prenatal care matter in promoting skilled institutional delivery? A study in rural Mexico. Matern Child Health J. 2006; 10(5):419-25. https://doi.org/10.1007/s10995-006-0079-x.

61. Mondal D, Galloway TS, Bailey TC, Mathews F. Elevated risk of stillbirth in males: systematic review and meta-analysis of more than 30 million births. BMC Med. 2014:12(1):220. https://doi.org/10.1186/s12916-014-0220-4.

62. Drevenstedt GL, Crimmins EM, Vasunilashorn S, Finch CE. The rise and fall of excess male infant mortality. Proc Natl Acad Sci. 2008;105(13):5016-21. https://doi.org/10.1073/pnas.0800221105.

63. Liselele HB, Boulvain M, Tshibangu KC, Meuris S. Maternal height and external pelvimetry to predict cephalopelvic disproportion in nulliparous African women: a cohort study. BJOG Int J Obstet Gynaecol. 2000;107(8): 947-52. https://doi.org/10.1111/j.1471-0528.2000.tb10394.x.

\section{Publisher's Note}

Springer Nature remains neutral with regard to jurisdictional claims in published maps and institutional affiliations.

Ready to submit your research? Choose BMC and benefit from:

- fast, convenient online submission

- thorough peer review by experienced researchers in your field

- rapid publication on acceptance

- support for research data, including large and complex data types

- gold Open Access which fosters wider collaboration and increased citations

- maximum visibility for your research: over $100 \mathrm{M}$ website views per year

At $\mathrm{BMC}$, research is always in progress.

Learn more biomedcentral.com/submissions 